\title{
Huge Dermoid Cyst 7 kg Weight in a Post-Menopausal Woman Mimicking a Malignant Ovarian Tumour: Rare Case with Review of Literature
}

\section{Rajshree Dayanand Katke*}

Obstetrics \& Gynecology Department, Cama \& Albless Hospital, India

\begin{abstract}
Benign Cystic Teratoma (Dermoid cyst) is the most common Germ cell tumor; it rarely grows larger than 10 $\mathrm{cm}$ in diameter and usually occurs in young women with peak incidence between the ages of 20 and 40 years. We report a case of an unusually massive benign cystic teratoma measuring $25 \times 25 \times 15 \mathrm{~cm}$ and weighing approx. $7 \mathrm{~kg}$, removed from a 53 year old post-menopausal female, multiparous woman who had been carrying the cyst over a period of two years. She underwent an exploratory laparotomy with ovarian mass resection total abdominal hysterectomy and bilateral salpingo-oophorectomy. Histopathological diagnosis confirmed the tumor to be a benign cystic teratoma.
\end{abstract}

Keywords: Benign cystic teratoma; Dermoid cyst; Exploratory laparotomy

\section{Introduction}

Germ cell tumors of the ovary form a group of neoplasms comprising of many individual and mixed entities. Approximately 25$30 \%$ of all ovarian tumors are of Germ cell origin and of these, $95 \%$ are benign and only 3-4\% are malignant. Benign cystic teratomas (Dermoid cyst) account for $10-20 \%$ of all ovarian neoplasms. They are encountered predominantly in women in their second and third decades of life and they rarely grow larger than $15 \mathrm{~cm}$. We present an unusual case of huge dermoid cyst of size $25 \times 25 \times 15 \mathrm{~cm}$ in postmenopausal women mimicking a hydatid cyst of liver and ovarian malignancy. Our case report emphasizes that dermoid cyst should be considered as differential diagnosis in case of huge abdominal lump and should be managed accordingly.

\section{Case Report}

53 year old postmenopausal multiparous woman came with distention of abdomen which had gradually increased over a period of 2 years. On examination, general examination was unremarkable. Per abdomen examination revealed a large mass arising from the pelvis, corresponding to 32 weeks size of gravid uterus, with regular margins, firm consistency, smooth surface and free mobility.

There was third degree uterovaginal descent on per speculum examination, with cystorectocoele. Per vaginal examination revealed a huge mass palpated through the fornices, uterus was not palpated separately and the mass was causing fullness in bilateral fornices as well as the Pouch of Douglas. Hence the findings of the abdominal examination were confirmed. There was no involvement of the rectal mucosa on per rectal examination.

All routine investigations were done and were found to be within normal limits. Tumour markers for epithelial ovarian malignancy were mildly raised, i.e., Serum CA $125-88 \mathrm{U} / \mathrm{ml}$, Serum CEA- $1.20 \mathrm{ng} / \mathrm{ml}$. Ultrasound findings were suggestive of a large cystic mass of size 30 $\times 25 \times 22 \mathrm{~cm}$ in size, probably of ovarian origin. Right ovary not seen separately. Left ovary normal.

Computerized Tomography (CT) of abdomen and pelvis was done which was suggestive of a large, right sided abdomino-pelvic cystic mass of size $32.5 \times 22 \times 22 \mathrm{~cm}$ with thickened peripheral walls with internal septations within with few areas of calcifications. It was extending from liver to pelvis giving the differential diagnosis of hydatid cyst or ovarian mass benign or malignant. There was no evidence of metastatic lesions

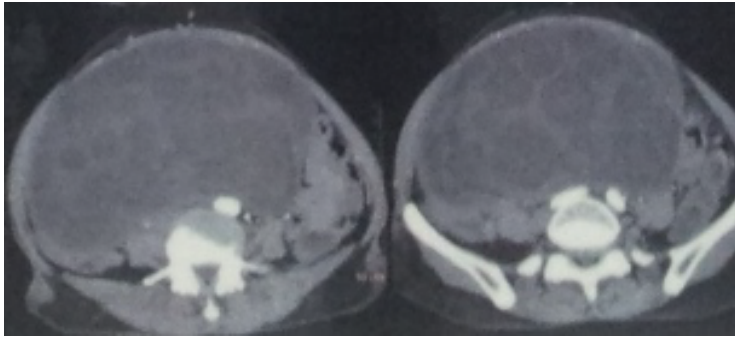

Figure 1: CT scan plate showing extension of mass.

in abdominal or pelvic cavity. Uterus with bilateral ovaries was normal (Figures 1.1 and 1.2).

Exploratory laparotomy was planned with frozen section at hand. In situ findings were suggestive of a huge ovarian mass of $35 \mathrm{~cm} \times 25$ $\mathrm{cm} \times 23 \mathrm{~cm}$ with regular margins, cystic in consistency, smooth surface, with a pedicle at the base containing dilated feeder vessels weighs 6 $\mathrm{kg}$. As there was overstretching of the in fundi bulopelvic ligament, primarily, ureteric dissection was done. Once the course of the ureter was identified, the pedicle clamped cut by cautery and ligated. Under vision the tumour was sent for frozen section which was suggestive of a dermoid ovarian cyst. Contralateral ovary appeared to be normal. Total Abdominal Hysterectomy with bilateral salpingectomy with right sided oophorectomy with removal of huge ovarian tumour was performed.

On gross examination, the tumour was $35 \times 25 \times 23 \mathrm{~cm}$ in size, with a single large cyst. The outer surface was smooth, with regular margins, cystic consistency and greyish yellow hue. Cut section of the mass showed large amounts of pultaceous material with engulfed hair. The cyst wall showed some amounts of cartilages. The histopathological

*Corresponding author: Rajshree Dayanand Katke, Obstetrics \& Gynecology Department, Cama \& Albless Hospital, Mumbai, Maharashtra, India, Tel: 91-022 22620390; Fax No: 91- 022-22621197; E-mail: drrajshrikatke@gmail.com

Received February 10, 2016; Accepted May 09, 2016; Published May 15, 2016

Citation: Katke RD (2016) Huge Dermoid Cyst 7 kg Weight in a Post-Menopausal Woman Mimicking a Malignant Ovarian Tumour: Rare Case with Review of Literature. Gen Med (Los Angel) 4: 241. doi:10.4172/2327-5146.1000241

Copyright: (๑) 2016 Katke RD. This is an open-access article distributed under the terms of the Creative Commons Attribution License, which permits unrestricted use, distribution, and reproduction in any medium, provided the original author and source are credited. 
Citation: Katke RD (2016) Huge Dermoid Cyst 7 kg Weight in a Post-Menopausal Woman Mimicking a Malignant Ovarian Tumour: Rare Case with Review of Literature. Gen Med (Los Angel) 4: 241. doi:10.4172/2327-5146.1000241

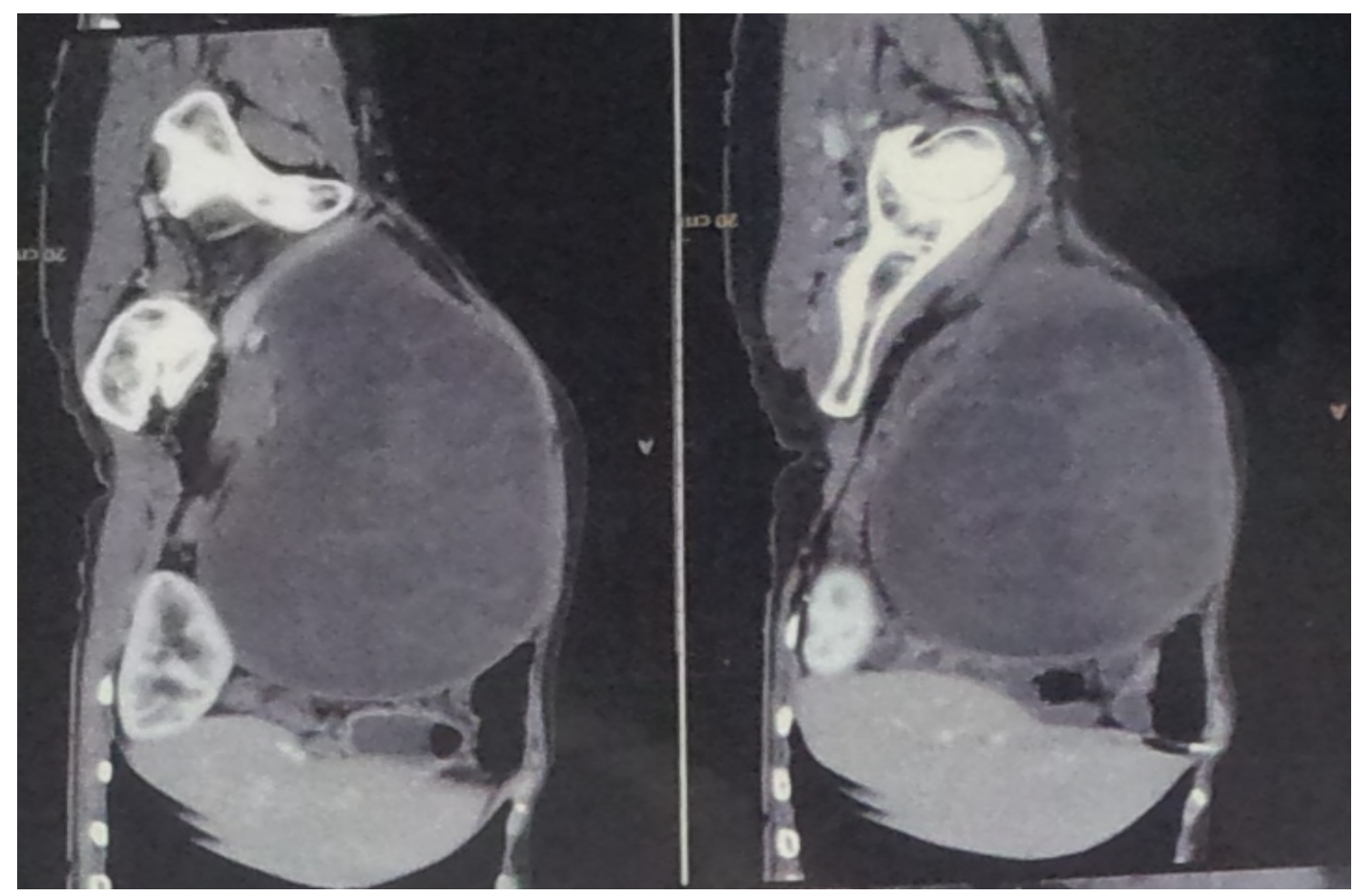

Figure 1.2: CT scan plate showing multiple cystic lesion seen within mass.

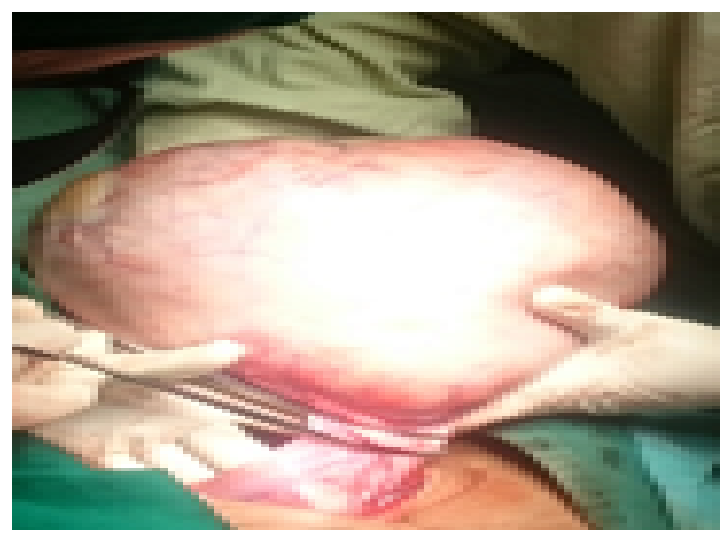

Figure 2.1: Intra operative clamping of pedicle of the tumor.

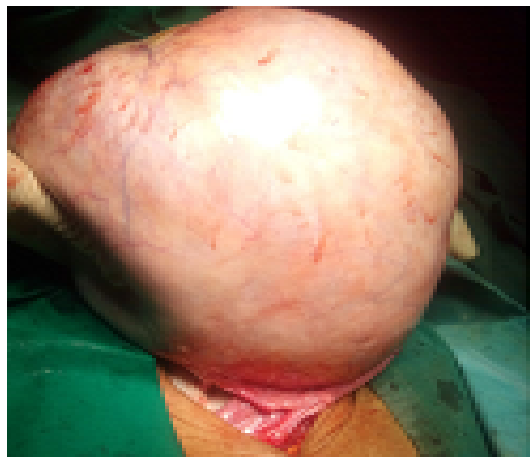

Figure 2.2: Ovarian mass with pedicle.

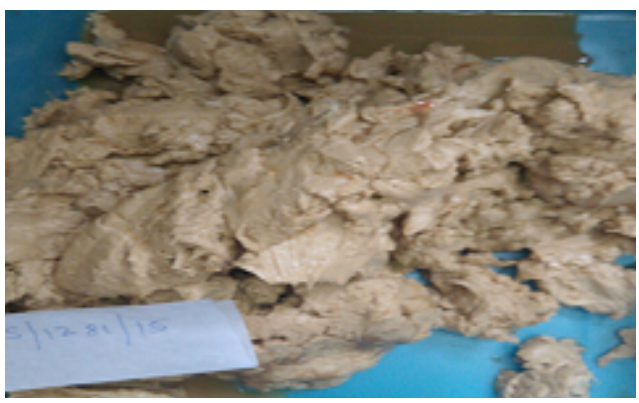

Figure 2.3: Sebacious material inside cyst.

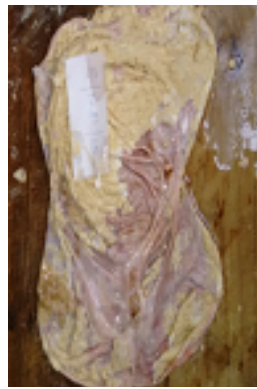

Figure 2.4: Cut section of dermoid cyst.

report confirmed the diagnosis i.e., mature teratoma. Postoperatively, the patient had an uneventful course in ward and was discharged into healthy life (Figures 2.1-2.4). 


\section{Discussion}

Benign cystic teratomas, often called Ovarian Dermoids, account for $97 \%$ of ovarian teratomas and $10-20 \%$ of ovarian neoplasms. They are usually around $5-15 \mathrm{~cm}$ in diameter, often heavy for their size and frequently on a long pedicle. These latter features account for a ready liability to torsion. The cyst can occur at any age, but $90 \%$ occur in women of reproductive age. Our Patient was 53 years old and postmenopausal and no diagnostic modality could diagnose the ovarian cyst as a dermoid.

Dermoid cyst, or mature cystic teratoma, is the most common type of ovarian germ cell tumor, comprising up to $30 \%$ of all masses [1]. It is common in younger age group below 20 years old and are in old age group [2]. They are bilateral in $10-13 \%$ of cases. The incidence of malignant elements in a teratoma is low (approximately 1-2\%) [3]. Gonadal dermoid cysts occur mostly during the reproductive years, between the ages of 20 and 40 years [4]. They are frequently multi-cystic and contain sebaceous fluid as well as hair, teeth, bone, and skin. Typically, these tumors contain mature tissues of ectodermal (skin, brain), mesodermal (muscle, fat), and endodermal (mucinous or ciliated epithelium) origin [5]. They have a characteristic CT scan appearance with fat/fluid level attenuation and calcification or ossification, as demonstrated. The classic sonographic appearance is of a hyperechoic mass known as a dermoid plug or Rokitansky protuberance. The Rokitansky protuberance is composed of the thickened area of ectodermal tissue from which hair and teeth arise. Pain is often related to the size of the mass, and ovarian torsion is common. Mature cystic teratomas grow slowly at an average rate of $1.8 \mathrm{~mm}$ each year, prompting some investigators to advocate non-surgical management of smaller $(6 \mathrm{~cm})$ tumours. All these features were not found in our case. There can be malignant transformation of mature teratoma. Also there is few cases reported in which beningn tumor (oftenly mucinous cystadenoma coexist with mature teratoma) [6].

Histopathologically in our case specimen specimen contain more of sebaceous and few hair follicles. Normally in mature dermoid cyst the tumors represent one form of ovarian germ cell tumor which contain variety of mature, well-differentiated tissue elements may be found from all three embryologic germ layers (ectoderm, mesoderm, endoderm). These tumors are often called "dermoid cysts" because they are mostly cystic and mostly contain ectodermal elements, typically resulting in the abundant hair seen here.

The cystic nature of a mature teratoma of ovary is seen here in this hemisected tumor mass. The most common tissue element of these teratomas is skin, so large amounts of hair and sebum are produced, leading to a challenging clean up problem in surgical pathology following dissection of these tumors. If these tumors are mostly solid, then they are often "immature" teratomas with less differentiated tissue.

\section{Histopathology of Dermoid Cyst}

The surgical management of benign cystic teratoma should be directed according to age, desire for further fertility and presence of concomitant pelvic pathology rather than size or the laterality status. Laparoscopic management of benign dermoid cysts is safe and effective and can therefore be highly recommended [7]. In Our patient as the tumour size was very huge reaching up to xiphisternum and CT scan was suggestive of neoplasia (malignant), hence decision of total abdominal hysterectomy with bilateral salpingo-oophorectomy with frozen section suggestive of mature teratoma was done in this case. This case highlights the very atypical features dermoid cysts (Figure 3).

Sometimes dermoid cyst present with complications such as torsion

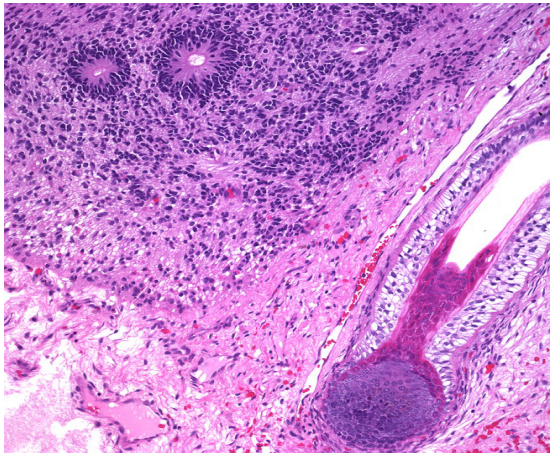

Figure 3: Histopathology of dermatoid cyst.

for which patient may present acutely or chronically which may need urgent surgical intervention.

\section{Conclusion}

There are many reported cases of ovarian tumor in postmenopausal women but a huge dermoid cyst in post-menopausal which cannot be diagnosed through any radiological modality is very rare. Even though dermoid cysts are rare in postmenopausal age group it should be considered as one of the differential diagnosis in case of suspicious ovarian masses.

\section{Acknowledgement}

Dr. Nishtha Tripathi (junior resident, OBGY), GGMC And Sir J.J. Group of hospitals, Mumbai.

\section{References}

1. Ayhan A, Bukulmez O, Genc C, Karamursel BS, Ayhan A (2000) Mature cystic teratomas of the ovary: case series from one institution over 34 years. Eur J Obstet Gynecol Reprod Biol 88: 153-157.

2. Katke RD (2014) Torsion of huge cystic teratoma of ovary with multiple fibroids uterus: a case report and review of literature. Int J Reprod Contracept Obstet Gynecol 3: 793-795.

3. Einarsson Jl, Edwards CL, Zurawin RK (2004) Immature ovarian teratoma in an adolescent: a case report and review of the literature. J Pediatr Adolesc Gynecol 17: $187-189$

4. Scully RE, Young RH, Clement PB (1998) Tumors of the ovary, maldeveloped gonads, fallopian tube and broad ligament. Atlas of tumor pathology. Third series, fascicle 23. Washington, DC: Armed Forces Institute of Pathology.

5. Outwater EK, Siegelman ES, Hunt JL (2001) Ovarian teratomas: tumor types and imaging characteristics. Radiographics 21: 475-490.

6. Morimitsu Y, Nakashima O, Kage M, Kojiro M, Kawano K (1991) Coexistence of mature teratoma and thecoma in an ovary. A report of two cases. Acta Pathol Jpn 41: 922-926.

7. Saks M, Deckardt R (1994) Laparoscopic treatment of benign ovarian dermoid cysts. J Am Assoc Gynecol Laparosc 4: S31-2. 